\title{
ELFRIEDE JELINEK - “SOMBRA (EURÍDICE DIZ)”
}

\section{SHADOW (EURYDICE SAYS)}

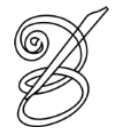 \\ Ruth BOHUNOVSKY* \\ Cristiane Gonçalves BACHMANN** \\ Universidade Federal do Paraná \\ Curitiba, Paraná, Brasil
}

Resumo: Propomos uma tradução literária para o português brasileiro, a partir do texto em alemão, de uma passagem da peça Sombra (Eurídice diz), da escritora austríaca Elfriede Jelinek. A peça, publicada em 2013, é uma reescrita moderna e feminista do mito grego de Orfeu e Eurídice. A tradução, seguida do respectivo texto de partida, é precedida de uma sucinta apresentação da obra e de sua autora, em que abordamos os aspectos mais relevantes desse texto teatral em termos de intertextualidade e características formais.

Palavras-chave: Elfriede Jelinek. Tradução literária. Eurídice e Orfeu. Intertextualidade. Feminismo.

Abstract: We propose a literary translation from German into Brazilian Portuguese of a passage from the drama Shadow (Eurydice Says), by Austrian writer Elfriede Jelinek. The play, published in 2013, is a modern and feminist version of the Greek myth of Orpheus and Eurydice. The translation, which is followed by its source text, is preceded by a concise presentation of the work and its author, in which we discuss some of the most relevant aspects of this theatrical text in terms of intertextuality and formal features.

Keywords: Elfriede Jelinek. Literary translation. Eurydice and Orpheus. Intertextuality. Feminism.

RECEBIDO EM: 3 de outubro de 2019

ACEITO EM: 26 de fevereiro 2020

PUBLICADO EM: março 2020 

urídice diz, ela não fala. Para Elfriede Jelinek, escritora austríaca premiada com o Nobel de Literatura em 2004, a "fala feminina é [...] uma usurpação fálica"1, uma "transgressão", não prevista na gênese dominada pelos homens. Na compreensão de Jelinek, isso diz respeito também à sua própria escrita. No texto teatral Sombra (Eurídice diz) [Schatten (Eurydike sagt)], a ninfa grega assume a voz e conta, pela primeira vez, a sua versão da história. Mesmo assim, ela não consegue sair da sombra nem assumir de fato o poder da fala. Ela apenas diz algo, mas suas palavras não interferem na realidade, como a fala dos homens.

Em toda a sua obra, Jelinek expõe discursos que trazem à tona relações de poder e de fala entre os sexos. Em Sombra..., a autora atualiza a história de amor entre Orfeu e Eurídice, em um mundo de presença e ausência que se tece proferido pela personagem feminina, permeado tanto do mito antigo quanto do universo contemporâneo. Porém, não há espaço para o otimismo.

Em linhas gerais, no mito grego, uma das grandes histórias de amor do Ocidente, Eurídice é picada por uma serpente e vai para o reino de Hades. Orfeu, poeta mítico que encantava com sua lira, não se conforma com a morte da amada e, por meio de seu belo canto e de sua determinação, consegue permissão para trazê-la de volta ao reino dos vivos, desde que não olhe para ela durante o retorno. Orfeu desobedece, de modo que a esposa precisa regressar ao Hades. Na narrativa da Grécia Antiga, cabe a Eurídice o papel da esposa que está à mercê da ação, da fala e do canto do homem.

No texto de Jelinek, Orfeu, famoso cantor de música pop, não tem voz. Em vez disso, torna-se alvo de vários comentários satíricos de sua esposa, que já se encontra no Hades e analisa a fundo o convívio que teve com o cantor. De modo perspicaz, Eurídice o apresenta como uma figura ridícula, machista e simplória: “ele é como um bebê, o que ele pega, ele agarra, chupa, e logo cospe fora, e então volta a cantar sem descanso"3.

Sob a ótica feminina de Eurídice - em cujas palavras identificamos várias passagens de textos de Sigmund Freud ${ }^{4}$-, Orfeu está sempre fugindo das massas histéricas de fãs femininas (quase crianças, ainda), de suas aproximações de viés sexual, e precisa da esposa para satisfazer a própria autoimagem, para espelhar-se nela, comprovando a própria genialidade. Para desempenhar o papel da mulher-companheira de um popstar, Eurídice deixou de lado sua vocação de escritora ("Eu escrevo, mas quem se importa"5). Agora, morta, Eurídice sente-se bem, pois, no reino das sombras, é invisível, portanto, livre.

Esse universo de sombras e de mortos-vivos está presente em várias outras obras de Jelinek, que o apresenta como o único em que mulheres conseguem assumir certo protagonismo 
(por exemplo, na peça Doença ou Mulheres modernas [Krankheit oder Moderne Frauen] ou no grande romance Os filhos dos mortos [Die Kinder der Toten]).

Embora resignada com sua própria invisibilidade, Eurídice não consegue atribuir-se plenamente a fala nem agir sobre sua própria existência. Também não é capaz de resistir à tentativa de Orfeu de resgatá-la. Mas ele, depois de tirá-la do Hades, perde-a, assim como no mito original, e volta sozinho para o mundo dos vivos. Entretanto, o motivo do fracasso de sua empreitada não é a força do amor romântico, mas a ansiedade por tornar pública sua experiência de salvador corajoso: Orfeu não quer conferir se a amada o está seguindo, ele quer fazer uma selfie (com Eurídice ao fundo, em segundo plano), e então saca seu celular para registrar o ato heroico do resgate da mulher do reino dos mortos. Aqui, Orfeu não olha para Eurídice senão através da lente da câmera de seu celular.

Outro ponto que diferencia o texto jelinekiano do mito grego e de outras reescritas dessa narrativa é que Eurídice não quer voltar com Orfeu ao mundo dos vivos (onde não consegue livrar-se do papel submisso tradicionalmente destinado às mulheres): ao contrário, ela está feliz com a ideia de continuar no reino dos mortos-vivos, invisível, sozinha, mas livre. O texto encerra com as palavras: “[...] não estou mais aí, eu sou”’. Somente não estando mais entre os homens é que ela, afinal, consegue ser. Mas talvez essa não seja exatamente uma diferença em relação à narrativa original e a outras já feitas - talvez, até agora, ninguém tenha perguntado a Eurídice se ela quer voltar com Orfeu.

Sombra (Eurídice diz) é uma das muitas peças de Jelinek escritas em forma de "superfícies textuais" ["Textflächen"] ${ }^{7}$. Trata-se de um termo usado para denominar peças escritas sem distribuição de papéis, "paisagens" linguísticas de parágrafos compridos e aparentemente sem estruturação. Jelinek afirma sobre seu teatro:

\footnotetext{
Minhas peças renunciam ao teatro psicológico. Os personagens não falam por si mesmos. Não são pessoas, nem seres humanos, mas modelos de linguagem. Elas se constituem daquilo que dizem, não daquilo que são. Elas afirmam algo sobre si, em vez de viver no palco. ${ }^{8}$
}

Ou seja, nada que lembre um drama tradicional. A propósito, em Sombra..., como em vários outros de seus textos teatrais, não há, também, rubricas, o que possibilita grande liberdade quanto ao formato da encenação. No que diz à realização cênica, Jelinek defende sempre a liberdade radical de diretores e atores, aceitando até mesmo que isso implique uma representação (às vezes, mais que provocativa) dela própria. 
Sombra... é um texto longo, em bloco, um monólogo da personagem Eurídice que se compõe de extratos discursivos de diversas fontes (Metamorfose, de Ovídio; a obra de Sigmund Freud - como mencionamos anteriormente -; A história maravilhosa, de Adelbert von Chamisso; a cultura pop etc.). A técnica de colagem é característica de toda a obra de Jelinek, tanto na prosa quanto nos textos teatrais. Em algumas encenações nos países de língua alemã, optou-se por dividir (ou multiplicar) a personagem e levar ao palco uma série de Eurídices, cada qual representando uma de suas facetas. No Brasil, a peça ainda não foi encenada. ${ }^{9}$

\section{REFERÊNCIAS}

Referência do texto de partida

JELINEK, Elfriede. Schatten (Eurydike sagt). 2013a. s/p. Disponível em: http://www.elfriedejelinek.com/fschatten.htm. Acesso em: 2 fev. 2020.

\section{Demais referências}

FREUD, Sigmund. Hemmung, Symptom und Angst. Wien: Internationaler Psychoanalytischer Verlag, 1926.

FREUD, Sigmund. Luto e melancolia (1917 [1915]). In: FREUD, Sigmund. Obras completas, volume 12: Introdução ao narcisismo, Ensaios de metapsicologia e outros textos (1914-1916). Traduzido por: Paulo César de Souza. São Paulo: Companhia das Letras, 2010. EPUB. Tradução de: "Trauer und Melancholie". Publicado primeiramente em Internationale Zeitschrift für ärztliche Psychoanalyse [Revista Internacional de Psicanálise Médica], v. 4, n. 6, p. 288-301. Traduzido de: Gesammelte Werke X, p. 428-446.

FREUD, Sigmund. Inibição, sintoma e angústia (1926). (Título original:). In: FREUD, Sigmund. Obras completas, volume 17: Inibição, sintoma e angústia, $O$ futuro de uma ilusão e outros textos (1926-1929). Traduzido por: Paulo César de Souza. 1. ed. São Paulo: Companhia das Letras, 2014. EPUB. Tradução de: "Hemmung, Symptom und Angst". Publicado primeiramente como volume autônomo em Viena: Internationaler Psychoanalytischer Verlag [Editora Psicanalítica Internacional], 136 p. Traduzido de: Gesammelte Werke XIV, p. 113-205.

FREUD, Sigmund. Trauer und Melancholie. In: Gesammelte Werke X. Chronologisch geordnet. Werke aus den Jahren 1913-1917. London: Imago Publishing Co., Ltd., 1949. p. 428-446.

JELINEK, Elfriede: Ich will kein Theater. Ich will ein anderes Theater. In: ROEDER, Anke (Hrsg.): Herausforderungen an das Theater. Frankfurt am Main: Suhrkamp, 1989. S. 143-161.

JELINEK, Elfriede. Textflächen. 2013b. Disponível em:

http://www.elfriedejelinek.com/ftextf.htm Acesso em: 3 fev. 2020. 
KON, Artur Sartori. "Eu escrevo, caso alguém se interesse" - A mulher e a artista na peça "Sombra", de Elfriede Jelinek. Revista Urdimento, v. 3, n. 33, dezembro de 2018, p. 28-48. Disponível em:

http://www.revistas.udesc.br/index.php/urdimento/article/download/1414573103332018028/9338 Acesso em: 10 fev. 2020.

ROEDER, Anke. (Hrsg.). Überschreitungen. Gespräch mit Elfriede Jelinek (1996). TABU: Bruch. Überschreitungen von Künstlerinnen. Interkulturelles Wissenschaftsportal der Forschungsplattform Elfriede Jelinek. Disponível em:

http://jelinektabu.univie.ac.at/moral/das-begehren-der-frau/anke-roeder/ Acesso em: 2 fev. 2020. 


\title{
PASSAGEM DE: “SOMBRA (EURÍDICE DIZ)"10,11
}

\author{
Autor: \\ Elfriede Jelinek \\ Traduzido por: \\ Cristiane Gonçalves Bachmann e Ruth Bohunovsky
}

\section{$[\ldots]$}

$\mathrm{Eu}$, pessoalmente, se você me perguntar, eu não conheço isso. Como poeta, não conheço isso. Deveria conhecer, mas não conheço. Meu cantor faz isso bem, sim, é verdade, faz isso tão bem, que acho que quando ele nasceu, quando se separou da mãe, essa Musa do Nãoseiquê, isso não pode ter sido de jeito nenhum tão doloroso para ele, que ele pudesse ter perdido a voz, olha, eu sou apenas uma ninfetinha, sou um nada em comparação a ele, só tento escrever um pouco, mas, olha, não funciona, ora, ainda criancinha, separado da mãe, da Musa, a própria mãe ainda era uma criançola, ora, não é possível que ele tenha vivenciado essa separação como uma experiência de medo. Impossível. Senão, ele não cantaria do jeito como ele canta, fazendo 266 amolecer até as pedras. Ele não conhece o medo, a não ser das garotas, não conhece o medo, de tão alto que ele canta. Só essas esgoeladas é que ele teme como o inferno. Só tem ou-isso-ouaquilo. Ou tem medo ou não tem. Sem terceira opção. E do jeito como está escorrendo de mim, claro que me dá medo também. Uma sensação que até o momento eu não conhecia e que eu me proibia. Mesmo assim, até então ele sempre costumava voltar, o medo sempre volta para mim, não importa o que eu faça. Já estou sentindo, não importa o que eu diga, ele vem, nem conheço outra coisa. Por muito tempo cometi o erro de relacioná-lo a certos órgãos, o medo, e também agora é isso que está acontecendo de algum modo, algo me mordeu, acho que uma cobra, eu vejo a ferida, ela não está onde costuma estar, uma ferida nova se abriu. Se bem que eu teria medo mesmo num vale ameno, mesmo passeando por lá, em qualquer lugar eu teria medo. Ele me domina completamente. Sempre me dominou. O que mais posso dizer sobre ele, senão que eu o sinto como se eu não fosse eu, mas sim um pedaço de lixo, não, veja só: meu armário! Esse, ninguém pode chamar de lixo, mas ele tem também guarda-pós, trenchcoats, casacos de swing, tudo que se pode vestir por cima, para que não vejam meu tremor por baixo, esse tremor com que pisoteio o chão. Nem pensar em coito, pisoteando desse jeito. Tudo menos isso, não isso de novo!, tudo com que tentei cobrir esse sentimento extremo de desprazer está aqui no meu armário. Sei lá. Agora eu mesma virei uma espécie de vestido, debaixo do qual está escorrendo alguma coisa. Eu sou aquilo que viveu apenas por um instante, deixando menos 
rastro do que a cobra que me deu o bote, de que me serve agora minha pele de roupa, minha ninhada de roupa, meu reduto nunca bem-sucedido? Com as minhas armas, com as armas de uma mulher, eu ponho o pé para fora e logo em seguida escorrego em mim mesma, nessa muda de pele, não tenho costume de pisar em algo assim, por acaso ela é minha? Ou da cobra? Não sei. Essa pele pertence a uma de nós. Não me serviram para nada, minhas roupas maravilhosas, agora eu mudo as roupas e, de repente, sou eu mesma que está mudada. Como gostaria de voltar para a beira da floresta, onde tudo aconteceu. Minhas amigas já se foram. São, elas próprias, chamadas de emergência, choram, cavoucam em busca de seus celulares, querendo um salvamento que não existe. De novo, choradeira em todo lugar, por toda parte. E eu, que sou tão sensível a ruído, ah, agora está bom, quase não ouço mais. Então já estou nas águas terminais, não, não nas águas termais, está pensando o quê. Não existe mais nada lá. Não, errado, ainda existe o meu vestido. Eu sou o vestido. Eu sou um vestido. Essa é a punição? Pelo quê? Por sempre me interessar apenas por roupa? Comprando feito maníaca, impulsionada de uma butique para a próxima, onde talvez tenha algo ainda mais bonito: esse também vai!, não desperdiçar perguntas sobre o salvamento, os trajes teriam sido meu salvamento, de quem? Não sei. O que devo eu ao medo? Não sei, honestamente, pois não conheço nenhum estado sem medo. Para os outros: resposta ao perigo. Para mim: sempre. Mesmo sem perigo. Sempre posso invocar esse estado, mas não preciso, pois ele sempre está aí. Sempre está à minha disposição. Antes, podia ser que tivesse algum sentido; agora, ele não é mais necessário, medo mesmo sem sentido e sem motivo. Essa cobra no capim, ainda nem vi, pois eu reajo a situações que ainda estão por vir com as medidas cabíveis contra elas; enquanto ainda as tomo, essas medidas, percebo que não servem para nada, o que impera, o que fica é apenas: medo. Eu mesma me antecipo em meu medo, não preciso de mais nada, o medo tem a mim, não eu que tenho medo, ele tem a mim. Roupas por cima, escolhidas a dedo, pois só debaixo das minhas roupas eu posso ser eu sem perigo, sem que alguém me veja, e depois calma, calmaria, até o próximo medo, e ele está sempre ali. Esperando que eu corra para o meu destino. O medo é um vestido, sempre preparado, desabotoado, e eu entro nele, não poderia dizer exatamente que me cubro com ele, pois nesse caso ele seria um corpo estranho, ele é meu vestido, sempre um outro, sempre o mesmo medo, nisso eu posso me fiar, disso eu tenho certeza. Mas de que isso me serve agora? Estou me perdendo, posso sentir isso. Já nem estou mais aí. Já estou enlutada pela minha própria perda, tenho certeza de que depois o cantor vai retomar isso muito mais a fundo, vai dedicar um bom tempo a isso, tempo para o luto, é preciso tomar tempo, todo o tempo necessário para um luto que se preze. O cantor examinará a realidade a fundo, perceberá que eu não estou mais 
ali, examinará novamente e se entregará à influência desse exame da realidade, totalmente entregue à influência do luto, sim, ele ficará assim, e o luto lhe exigirá, de modo categórico, que neste exato momento se separe de mim, seu objeto, pois meu Eu, esse objeto, já não existe mais. Ele vai ter que passar por esse trabalho, essa regressão de mim, do objeto, seu objeto, sim, isso é importante, não ria!, de mim, que me tornei preciosa, justamente porque sou o objeto dele, e ele terá que realizar essa regressão de mim, do objeto, em todos os níveis e em todas as fases de sua vida, realizar com esmero, em todas as situações em que o objeto, eu, ou seja, o objeto que era alvo de alto investimento, eu era o principal investimento, sem dúvida, um alto investimento, talvez ele tenha apostado demais em mim, pode ser, talvez ele tenha apostado errado, talvez apenas numa nota, apostou numa nota errada, com esse barulho todo ninguém vai escutar mesmo, apostou errado e deu errado, pode ser isso, mas ele terá que aceitar o caráter doloroso dessa separação, terá que se adaptar, então vai ter que se adaptar e terá que aceitar o alto e inalcançável investimento nostálgico de mim, pois já terei ido, já era, perdu, canoa virada, ele que aceite de uma vez por todas, que eu, o objeto, terei desaparecido, sim senhor, esse caráter doloroso que terá a regressão de seu objeto, ou seja, minha própria regressão, estou pensando,

268 é óbvio, na minha regressão como pessoa, tudo claro até aqui?, então, esse caráter doloroso dessa separação, ele vai ter que aceitar, ele vai, quem, ele?, o que é que vai acontecer?, então, o caráter doloroso da nossa separação vai se fazer sentir para sempre, mesmo depois de ele ter aceitado, o cantor, sempre de novo, e mesmo depois que ele tenha aceitado já há um bom tempo, depois de ter aceitado que eu, seu objeto, sumi definitivamente, vai ter que engolir, não lhe resta outra saída, e depois que ele sacar isso (ou seja, provavelmente nunca!, do jeito como eu o conheço, pois ele é como um bebê, o que ele pega, ele agarra, chupa, e logo cospe fora, e logo volta a cantar sem descanso, pois acabou de ter uma experiência, a experiência de que podemos ficar com tudo que pegamos, pois merecemos, pertence a nós que o máximo possível pertença a nós, isso me parece óbvio), depois de pescar isso, ele vai reconhecer esse investimento nostálgico de mim, de seu objeto, em todas as situações, em todas as situações reprodutíveis semelhantes, sempre como vínculo comigo, seu objeto, ainda que deva, na verdade, aprender a desatar o vínculo comigo, seu objeto, agora, afinal e definitivamente. Porque não há outro caminho. Vai ter que se desatar de mim; eu, da minha parte, que nem é mais minha, já me desatei faz tempo, não é tão ruim assim, de uma hora para outra ficar imprudente e irresponsável, deixar seus trajes para trás e dar o fora, sair fora de si próprio, simplesmente ir embora. Me deixar, finalmente me deixar ser, deixar sozinha, se bem que já estou, ele só não o aceitou, me deixar solta nesta paisagem que, de repente, me parece ser a mais divertida, 
luminosa, agradável, porque eu finalmente posso ir: ele não vai conseguir isso. Não vai conseguir me deixar ser. Ele não me fez, mas não me deixará ser. Vai querer me enfiar de volta no meu próprio Ser, já estou até vendo. Como ele está vinculado apenas a si mesmo, terá que vivenciar de novo, toda vida, em cada situação possível, a separação de mim, seu objeto amado, e vai querer acabar com isso, então vem me buscar. Talvez ele já suspeite de que não saberá lidar com essa separação, de que essa separação deverá se repetir para sempre, isso não pode ser nada agradável, quase dá para sentir pena dele, mas ele sempre estará lá, bem ali onde deveria finalmente desatar seu vínculo comigo, seu objeto amado, vai querer é justamente reatar esse vínculo, sim, precisará compulsivamente reatá-lo o tempo todo. Não vai dar para eu ir! É isso que ele vai dizer. Ele não me deixará. Não me deixará ir. Ele vai me enxergar por toda parte, à beira da floresta, nas copas das árvores, ou o que quer que a linguagem referente a natureza diga, eu não falo essa linguagem, ela me aborrece, leiam-na em outro lugar, contemplem-na em outro lugar, no cinema, na televisão, onde quer que seja, por mim, podem contemplar a natureza até mesmo in natura, mas a mim ela aborrece, ainda que, sim, também eu esteja sujeita à natureza, algo que neste momento preciso dolorosamente reconhecer. Pois bem, eu vou então contemplar a natureza enquanto ela ainda existe, podem ficar olhando com esses olhos arregalados por horas, não vai mudar nada, a natureza também vai desaparecer, vai desaparecer depois de mim, sim, claro, vai desaparecer, não hesitem em consultar tudo o que ela tem a oferecer, ainda tem a oferecer, mais ainda de tudo ela tem a oferecer!, confiram no Google Earth, mas eu não faço isso, a natureza não é bem a minha praia, nunca percebi isso tanto como agora, neste instante em que ela está me deixando, minha natureza, tchau-tchau e se cuide!, tanto faz, eu a conheço, mas exatamente porque a conheço é que não gostaria de estreitar relações com ela, então mentalizem uma dessas descrições da natureza, podem pegála onde vocês quiserem. E onde quer que ele fique aprisionado nessa descrição e onde quer que ele pegue seu instrumento, meu cantor, ele vai, eu já disse, mas é tão importante que vou repetir mais uma vez e toda vida: ele vai ter que reatar o vínculo com seu objeto amado, ou seja, eu, em vez de desatá-lo. Sempre acoplar, mesmo quando já nenhum trem estiver mais ali! Sempre atrelar tudo, interligar tudo, mesmo quando não estiver mais ali. Bem, eu não sou muito objetiva nesse assunto, sou apenas objeto, isso é muito pouco, pois não pode decidir-se, nem mesmo pela vida pode decidir-se, e vejo isso tão claro diante de mim, como se ainda pudesse vivenciálo: o intenso investimento nostálgico, e cada vez maior pela sua permanente insaciabilidade, esse intenso investimento nostálgico de mim, do objeto desaparecido e perdido, produzirá as mesmas condições econômicas que o investimento da dor de um ferimento no corpo, então, 
imaginem só, ele sentirá tanta dor quanto eu, por causa da picada dessa cobra ou o que quer que seja isso que acaba de me matar, ai! Então será isso mesmo que o pobre coitado vai sentir para sempre, repetidamente!, e esse constante investimento da dor causada pela ausência de mim, de seu objeto, tornará possível para ele ignorar o pré-requisito da origem periférica da dor física. Bem, a minha dor ele vai ignorar de qualquer jeito, não consegue e certamente nem quer imaginá-la, essa dor ele desconsidera sob esse Sol ofuscante que já não me enxerga mais, seu pai, o Sol, o Apolo em sua forma prima, não, não com rima, isso é um capítulo à parte, o pai dele me ofuscou desde o início, meus pequenos poemas não eram nada para ele, o radiante no seu carro, no seu carro celeste, talvez seja por isso que seu filho, o cantor, é tão insosso, tão parado, as meninas é que fazem todo o trabalho de se esgoelar, ele não faz nada, ele nunca faz absolutamente nada, já o seu pai esteve sempre naquele sobe e desce, e o filho não queria repetir isso, ter que ficar sempre assistindo ao Sol, seu papai, subir e descer, é quase tão ruim quanto entrar e sair, tudo que vem dos homens é de algum modo muito monótono, e até eles dominarem o segundo tom pode demorar. Sem sol não existiríamos, certo, reconheço isso, precisamos dele, mas não é grande coisa isso que somos, como é fácil perder um de nós, e eu já nem existo mais, mas não é grande coisa isso que não existe mais, e eu posso garantir: não é tão ruim assim; o deus do Sol quer me controlar?; se de fato eu desapareci, se me tornei uma sombra que, lamentável!, também não existe sem ele? Infelizmente é verdade: só ele consegue produzir sombra. Certo, disso ele tem o monopólio. Mas disso ele não se orgulha; como ele sempre reaparece ali; como ele (escutamos um relincho berrante, logo depois uma sibilante extinção), empinando-se, freia, pula para fora, olha se todas as sombras estão lá e se a cor que ele previu para a luz deu certo, e testa isso exatamente na luz que ele mesmo produziu; como ele aparece e de novo desaparece, tudo na mais tediosa estereotipia, sim, exatamente como minha obra, que bom que você está me dizendo isso, mas não precisava!, eu mesma sei, eu sei, minha obra é monótona, mas o caminho dele é igualzinho: monótono, só tem mesmo a via celeste, que vocês podem muito bem imaginar como um desvio ermo em algum lugar nos pampas, e lá ele transita, e vai subindo e de novo descendo, ele me ofuscou, como tantos outros, como mais cedo ou mais tarde todos; ele não me enxerga mais, eu já estou longe quando ele aparece, o Apolo, o ogrinho, ops, o sogrinho!, será que já sabe que não lhe restará outra opção a não ser desaparecer novamente, sumir, mesmo que apenas por algumas horas, pois pelo menos assim, na Terra ele não terá mais nada que fazer. Ele precisa cair fora, assim como eu, mesmo que não para sempre. Ele volta. Sempre volta. Ao contrário de mim, ele nunca some para sempre, o deus do Sol, ele pode até cair, mas sempre levanta e segue seu caminho. Senão, ficaria sempre escuro. E nem 
sequer seu filho, o cantor, me enxerga mais, isso acaba mesmo com ele, sim, isso acaba com ele!, pois só é capaz de me reconhecer em relação a si próprio, claro, isso vale para muitos, não é nada de mais, mas mas mas, o que eu queria dizer, é que a transição dessa dor física que sempre vai se fazer sentir quando ele precisar reconhecer a ausência de seu objeto, nesse caso minha ausência, essa passagem corresponde à mudança, ora, a transição do Eu-sei para o Eunão-sei normalmente corresponde, no caso de pessoas normais, que não são cantores, a absolutamente nada, nenhuma correspondência, nenhum acerto, no caso de pessoais normais isso não encontra nenhuma correspondência, ou eu não os conheço, os normais. Exatamente! Enquanto alguns estão trabalhando duro em cima do palco, e as menininhas com suas bocas de boceta de plaina elétrica, que só dominam três notas e nada mais, uma acima, uma abaixo e uma no meio, e nenhuma delas é agradável para o deleite humano, elas fogem se esgoelando dos olhares severos e repreendedores de suas mães, que, muito tempo atrás, também corriam com suas barracas para os festivais na lama, onde os banheiros químicos transbordam de tanta comoção interna. Que maravilha essa lembrança e aquela lá também! Com nossos stars claro que isso é diferente, com eles tudo é diferente, mas o que o cantor vai fazer com aquelas que ficam tirando para fora suas genitálias e abrindo bem na cara dele, e a genitália feminina está simplesmente por toda parte, mesmo na sua fase mais precoce, podemos olhar para onde quisermos, está simplesmente em toda parte, as meninas com suas fendas traiçoeiras, são como montes de areia, bancos de areia, buracos de areia movediça, engolem qualquer um, não devolvem ninguém, estão prontas para alguém que não seja ninguém ou para ninguém que seja alguém, não importa quem seja, se for um grupo, melhor ainda, muitos de uma única vez!, então aquelas todas que ficam se esgoelando aaaaaah aaaaah aaaaaah!, melhor bomba da pista de dança, temos então uma transição, o que era mesmo que eu queria dizer?, uma transição que no caso de pessoas normais não corresponde a nada?, como eu já comentei por equívoco em algum momento, mas que corresponde exatamente à mudança de investimento narcísico para o de objeto, né. A transição, portanto, corresponde a algo, sim, mas para isso seria preciso antes de tudo ver, além de si mesmo, outra coisa, um outro, pelo menos um!. Pois é, um elas conseguem ver, sei lá quem, não, acho que sei quem, mas sei lá se é mesmo verdade aquilo que o cantor canta. Acredito que agora ele esteja tranquilo, de qualquer forma. A dor fantasma de uma perda leva as pessoas normais a procurarem outro objeto que, por sua vez, pode novamente lhes causar dor. Uma dor completamente nova. Mas, ainda assim, uma dor. As pessoas reprimem isso porque acreditam que querem diversão, mas o que elas querem é dor. Quanto mais querem ter, mais querem que falte algo. Para que possam então voltar a ter algo novo. Você ainda lembra 
que será a minha ausência, a ausência do objeto amado, o que vai levar à necessidade da mudança do investimento do objeto? Minha morte? Minha ausência? Mas não no caso dele, não no caso dele, no caso dele não é bem assim que funciona, já estou prevendo isso. Eu o conheço. Ele não vai se contentar. Ele vai tentar me encontrar. Vai atentar para o meu rastro. A mim, seu objeto, ele superestimou, isso foi um equívoco desde o começo, um equívoco típico de cantor, uma nota errada, isso vai de algum modo dar a nota errada ao seu luto, já estou ouvindo isso, eu escuto o futuro, ela está definitivamente errada e cada uma das suas notas também está errada, ele vai cantar uma nota errada, já estou ouvindo isso, antes mesmo de ele iniciar, ninguém mais está ouvindo, já não ouvem nada, essas esgoeladas que ouvem apenas a ele, mas não o dito, e aquilo que ouvem é também nada, mas eu ouço, ele me superestimou como seu objeto, não é de se admirar, ele foi o chefe de investimento de mim, seu objeto, e ele me concedeu um papel elevado demais, olha, eu disse concedeu, porque foi ele quem criou esse lugar para mim, eu não fiz nada, mas ele, ele me superestimou em exagero, e esse papel de objeto altamente investido que ele criou para mim de forma explícita (eu não pedi isso, acreditem em mim!), desempenha mais ou menos o papel do local no corpo que está ferido e que, por causa do aumento de estímulo, está coberto apenas de forma provisória. Para os que ficam, os mortos sempre se tornam mais estimulantes do que jamais foram. Agora, ele me enxerga como parte do seu corpo, ele não consegue me enxergar de outro jeito. Óbvio. E a natureza contínua desse processo de investimento e a impossibilidade de inibi-lo, que corresponde à natureza contínua e à impossibilidade de inibir sua dor, que ele precisa sentir como verdadeira e terrível dor física, produzem uma situação, produzem nele uma situação que, como é que eu posso dizer, ah, sim, alguém já disse isso por mim, obrigada, então, a continuidade e a impossibilidade de erigir, ops, de se exibir, não, também não, de inibir, produzem nele, então, uma situação de total desamparo. Ou prolongam essa situação, pois nunca o vi senão desamparado. Parece até que já estou vendo a cena diante de mim, eu ainda deitada na grama, aos poucos sombreando-me e sendo sucateada, do alto vem um raio, mas já não me ilumina mais, da montanha vem uma tempestade, mas já não me move mais, o que é que eu quero aqui, se nem sou nenhum desses seres superiores que têm algum direito? O que é que eu quero aqui? Já nem mais coberta pela pele? Sombra? Já sem essência e sem ser essencial, mas isso eu nunca fui.

$[\ldots]$ 


\title{
PASSAGEM DE: "SCHATTEN (EURYDIKE SAGT)"
}

\author{
Elfriede Jelinek
}

\section{$[\ldots]$}

Ich persönlich, wenn Sie mich fragen, ich kenne das nicht. Als Dichterin kenne ich das nicht. Ich sollte es kennen, aber ich kenne es nicht. Mein Sänger macht das gut, ja, stimmt schon, der macht das so gut, daß ich mir denke, er kann bei der Geburt die Trennung von seiner Mutter, dieser Muse für Keineahnungwas, keinesfalls als so schmerzhaft empfunden haben, daß es ihm die Stimme verschlagen hätte, bitte, ich bin ja nur ein Nymphchen, ich bin ja ein Nichts dagegen, versuche halt auch, ein wenig zu schreiben, aber bitte, es geht nicht, also von der Mutter, der Muse, als Kind getrennt, Mutter selbst noch ein Kindwesen, also die Trennung von ihr kann er nicht als Angsterlebnis empfunden haben, unmöglich. Sonst würde er nicht dermaßen singen können, daß es die Steine erweicht. Der kennt keine Angst, außer vor den Mädels kennt er keine Angst, so lauthals wie der singt. Nur die Kreischerinnen fürchtet er wie die Hölle. Da gibt es nur ein Entweder-Oder. Da gibt es nur Angst oder keine Angst. Ein Drittes nicht. Und so, wie es da aus mir herausrinnt, macht es mir natürlich auch Angst. Ein Gefühl, das ich bislang nicht kannte und das ich mir untersagte. Und doch, bis jetzt ist es immer wiedergekommen, die Angst kommt immer wieder zu mir, da kann ich machen, was ich will. Ich fühle sie schon, was ich auch sage, sie kommt, und ich kenne kaum etwas anderes. Ich habe lang den Fehler gemacht, sie auf bestimmte Organe zu beziehen, die Angst, und auch jetzt stimmt das ja irgendwie, da hat mich was gebissen, ich glaube, eine Schlange, ich sehe die Wunde, sie ist nicht dort, wo sie sonst ist, eine neue Wunde hat sich aufgetan. Aber da ich auch Angst hätte in einem milden Tal, ob ich auch wanderte dort, ich hätte überall Angst. Sie beherrscht mich ganz. Hat sie immer getan. Was kann ich mehr von ihr sagen, als daß ich sie empfinde, als wäre ich nicht ich, sondern ein Stück Dreck, nein, schauen Sie: mein Garderobenschrank! Den kann keiner Dreck nennen, aber er enthält auch Staubmäntel, Trenchcoats, Swingermäntel, etwas, das man drüberziehen kann, daß man darunter mein Zittern nicht sieht, mit dem ich die Erde stampfe. Kein Gedanke an Koitus bei diesem Stampfen. Alles eher als der, nicht der schon wieder!, alles, was ich über diese extreme Empfindung von Unlust zu hängen versucht habe, befindet sich in diesem Schrank hier. Ich weiß nicht recht. Jetzt bin ich selber eine Art Kleid, unter dem es herausrinnt. Ich bin das, was nur kurz gelebt hat, noch weniger Abdruck im Boden als die Schlange, die sich auf mich gestürzt hat, was nützt 
mir nun meine Kleiderhaut, meine Kleiderbrut, mein nie gelungener Hort? Mit meinen Waffen, mit den Waffen einer Frau trete ich hinaus und gleite sofort auf mir selber aus, auf dieser abgeworfenen Haut, bin nicht gewohnt, auf sowas zu gehen, gehört die etwa mir? Oder der Schlange? Ich weiß es nicht. Einer von uns beiden gehört diese Haut. Sie haben mir nichts genützt, meine herrlichen Kleider, ich werfe sie nun ab, und da bin auf einmal ich selbst das Abgeworfene. Gerne würde ich wieder am Waldrand stehen, wo es passiert ist. Meine Freundinnen sind fort. Sind Notrufe selbst, weinen, graben nach ihren Handys, wollen eine Rettung, die es nicht gibt. Schon wieder Geheule überall, allerorten. Wo ich doch so lärmempfindlich bin, ach, jetzt ist es gut, ich höre es kaum noch. Bin wohl schon im Keinort, aber nein, doch nicht im Kurort, wo denken Sie hin. Nichts ist mehr da. Nein, stimmt nicht, mein Kleid ist noch da. Ich bin das Kleid. Ich bin ein Kleid! Ist das die Strafe? Wofür? Daß mich immer nur Kleider interessiert haben? Manisch einkaufen gegangen, getrieben von einer Boutique in die nächste, wo es vielleicht noch Schöneres gab: das auch noch!, keine Fragen an Rettung vergeudet, die Hüllen wären meine Rettung gewesen, vor wem? Ich weiß es nicht. Was verdanke ich der Angst? Das weiß ich nicht, ehrlich gesagt, denn ich kenne angstlose Zustände ja nicht. Bei andren: Antwort auf Gefahr. Bei mir: immer. Auch ohne Gefahr. Ich kann diesen Zustand immer herbeirufen, тиß es aber nicht, er ist sowieso immer da. Steht mir immer zur Verfügung. Früher mag er einen Sinn gehabt haben, jetzt ist er nicht mehr nötig, Angst auch ohne Sinn und ohne Anlaß. Diese Schlange im Gras habe ich gar nicht gesehen, ich antworte ja auf spätere Zustände mit den geeigneten Maßnahmen gegen sie; während ich sie noch anwende, diese Maßnahmen, merke ich, daß sie nichts nützen, es herrscht, und es bleibt nur: Angst. Ich nehme mich selbst in meiner Angst vorweg, ich brauche nichts mehr, die Angst hat mich, nicht ich habe Angst, sie hat mich. Kleider drüber, lange ausgesucht, denn nur unter meinen Kleidern kann ich gefahrlos ich sein, ohne daß mich jemand sieht, und dann Ruhe, Beruhigung, bis zur nächsten Angst, und die ist immer schon da. Sie wartet, daß ich in mein Schicksal eile. Die Angst ist ein Kleid, das sich bereithält, offenhält, und ich gehe in sie hinein, könnte nicht direkt sagen, daß ich sie mir überstülpe, dann wäre sie ja ein Fremdkörper, sie ist mein Kleid, immer ein andres, immer dieselbe Angst, darauf kann ich bauen, die ist mir sicher. Aber was nützt mir das jetzt? Ich verliere mich, das spür ich. Ich bin schon weg. Ich trauere schon um meinen eigenen Verlust, bin sicher, der Sänger wird das später noch viel gründlicher nachholen, der wird sich Zeit dafür nehmen, Zeit für Trauer, die muß sein, soviel Zeit muß sein, daß man anständig trauert. Der Sänger wird die Realität gründlich prüfen, er wird merken, daß ich nicht mehr da bin, er wird noch einmal prüfen und unter den Einfluß dieser 
Realitätsprüfung gelangen, total unter den Einflu $\beta$ der Trauer gelangen, ja, das wird er, und die wird von ihm kategorisch verlangen, daß er sich von mir, seinem Objekt, jetzt trennen muß, weil mein Ich, dieses Objekt, doch gar nicht mehr besteht. Er wird dann die Arbeit zu leisten haben, diesen Rückzug von mir, dem Objekt, seinem Objekt, ja, das ist wichtig, lachen Sie nicht!, von mir, die ich wertvoll geworden, gerade weil ich sein Objekt bin, und er wird diesen Rückzug von mir, dem Objekt, auf allen Ebenen und in allen Phasen seines Lebens durchzuführen haben, ordentlich durchzuführen haben, in allen Situationen, in denen das Objekt, ich, das Objekt also Gegenstand hoher Besetzung war, ich war die erste Besetzung, kein Zweifel, eine hohe Besetzung, vielleicht hat er mich zu hoch angesetzt, mag sein, vielleicht hat er mich falsch angesetzt, vielleicht nur einen Ton, nur einen Ton falsch angesetzt, bei dem Lärm hört das eh keiner, falsch angesetzt und falsch gebracht, das mag sein, aber er wird den schmerzlichen Charakter dieser Trennung akzeptieren müssen, er wird sich fügen müssen, er wird sich dann fügen müssen und die hohe und unerfüllbare Sehnsuchtsbesetzung von mir, die ich weg sein werde, futsch, perdu, abgetaucht, wird er für immer akzeptieren müssen, denn ich, das Objekt, werde eben fort sein, jawohl, fort, und das wird er, fürchte ich, diesem schmerzlichen Charakter, den der Rückzug seines Objekts haben wird, nämlich mein Rückzug persönlich, ich meine natürlich meinen Rückzug als Person, alles klar soweit?, also diesem schmerzlichen Charakter dieser Trennung wird er sich fügen müssen, er wird sich, wer, er?, was wird passieren?, also der schmerzliche Charakter unserer Trennung wird sich immer wieder einstellen, auch wenn er sich gefügt hat, der Sänger, immer wieder aufs neue, und sogar nachdem er sich längst gefügt haben wird, nachdem es sich gefügt hat, daß ich, sein Objekt, endgültig verschwunden bin, wird er das hinnehmen müssen, es wird ihm nichts andres übrigbleiben, und nachdem er das kapiert haben wird (so, wie ich ihn kenne, wahrscheinlich nie!, der ist wie ein Säugling, was er hat, das hält er fest, an dem saugt er, und dann spuckt er es wieder aus, und dann singt er gleich wieder fleißig, weil er eine Erfahrung gemacht hat, die Erfahrung, daß man alles behalten darf, was man hat, weil es einem zusteht, es gehört sich, daß einem möglichst viel gehört, das leuchtet mir ein), nachdem er das geschnallt hat, wird er diese Sehnsuchtsbesetzung von mir, seinem Objekt, in allen Situationen, in allen ähnlichen reproduzierbaren Situationen immer wieder als Bindung an mich, sein Objekt, erkennen, wo er doch lernen sollte, die Bindung an mich, sein Objekt, jetzt endlich und endgültig zu lösen. Da führt kein Weg daran vorbei. Er wird sich von mir lösen müssen, ich für meinen Teil, der aber nicht mehr meiner ist, ich habe mich ja längst gelöst, gar nicht so schlecht, plötzlich leichtsinnig zu sein und unverantwortlich, seine Hüllen liegenzulassen und abzuhauen, aus sich selbst 
heraus, einfach wegzugehen. Mich zu lassen, mich endlich sein zu lassen, allein zu lassen, was ich ohnedies bin, er hat das nur nicht akzeptiert, mich loszulassen in dieser Landschaft, die mir plötzlich total lustig erscheint, hell, freundlich, da ich endlich gehen kann: Das wird er nicht schaffen. Er wird es nicht schaffen, mich sein zu lassen. Er hat mich nicht gemacht, aber er wird mich nicht sein lassen. Er wird mich in mein Sein wieder hineinstopfen wollen, das sehe ich kommen. Da er nur an sich selbst gebunden ist, wird er in jeder möglichen Situation die Trennung von mir, seinem geliebten Objekt, immer wieder aufs neue erleben müssen, und das wird er beenden wollen, indem er mich wieder holen geht. Vielleicht ahnt er es schon, daß er mit dieser Trennung nicht fertig werden wird, daß diese Trennung immer wieder stattfinden wird müssen, das kann nicht angenehm sein, er kann einem fast leid tun, aber er wird immer dort, wo er endlich die Bindung an mich, sein geliebtes Objekt, lösen wird sollen, diese Bindung erst richtig herstellen wollen, ja zwanghaft immer wieder herstellen müssen. Es geht nicht, daß ich gehe! Das wird er sagen. Er wird mich nicht lassen. Er wird mich nicht gehen lassen. Überall wird er mich sehen, am Waldrand, in den Wipfeln der Bäume, oder was die Natursprache sonst sagt, ich spreche sie nicht, sie langweilt mich, lesen Sie sie woanders, schauen Sie sie woanders an, im Kino, im Fernsehn, wo auch immer, schauen Sie die Natur meinetwegen auch in natura an, aber mich langweilt sie, obwohl ja auch ich der Natur unterworfen bin, was ich grade schmerzlich zur Kenntnis nehmen muß. Bitte, schau ich mir halt brav die Natur an, solang sie noch da ist, glotzen Sie von mir aus stundenlang, es wird sich kaum was ändern, die Natur wird auch verschwinden, nach mir wird sie verschwinden, ja, klar, verschwinden wird sie, schlagen Sie ruhig nach, was sie alles zu bieten hat, noch zu bieten hat, nicht noch alles zu bieten hat!, schlagen Sie sie in Google Earth auf, aber ich mach das nicht, die Natur ist nicht so meins, ich habe das noch nie so gemerkt wie eben jetzt, da sie mich verläßt, meine Natur, baba und fall net!, egal, ich kenne sie, aber gerade weil ich sie kenne, möchte ich die Bekanntschaft mit ihr nicht unbedingt vertiefen, also stellen Sie sich eine Naturschilderung vor, nehmen Sie sie, wo immer Sie sie herkriegen können. Und wo auch immer er in dieser Schilderung gefangengenommen sein wird und zu seinem Instrument greifen wird, mein Sänger, wird er, ich sagte es schon, aber es ist so wichtig, daß ich es noch einmal sage und immer wieder: wird er also die Bindung an sein geliebtes Objekt, nämlich mich, herstellen müssen anstatt sie zu lösen. Immer ankoppeln, auch wenn gar kein Zug mehr dasteht! Immer alles anhängen, alles zusammenhängen, auch wenn es überhaupt nicht mehr da ist! Na ja, ich bin nicht objektiv in dieser Sache, bin nur Objekt, das ist viel weniger, weil es sich nicht entscheiden kann, und fürs Leben kann es sich schon gar nicht entscheiden, aber ich sehe das so klar vor 
mir, als könnte ich es noch erleben: Die intensive, infolge ihrer Unstillbarkeit stets anwachsende Sehnsuchtsbesetzung von mir, dem vermißten, verlorenen Objekt, wird dieselben ökonomischen Bedingungen herstellen wie die Schmerzbesetzung einer verletzten Körperstelle, also stellen Sie sich vor, es wird ihm so weh tun wie mir der Biß dieser Schlange oder was das ist, das mich jetzt getötet hat, aua! Also das wird es sein, was das arme Schwein immer wieder aufs neue spüren muß!, und diese fortwährende Schmerzbesetzung durch das Fehlen von mir, seinem Objekt, wird es ihm möglich machen, von der peripherischen Bedingtheit des Körperschmerzes wieder abzusehen. Na ja, von meinem Schmerz kann er sowieso absehen, den kann und will er sich natürlich nicht vorstellen, diesen Schmerz klammert er aus unter der blendenden Sonne, die mich nicht mehr sieht, sein Vater, die Sonne, der Apoll in Reinform, nein, nicht in Reimform, das ist wieder ein eigenes Kapitel, sein Vater hat mich von Anfang an ausgeblendet, meine kleinen Dichtungen waren nichts für ihn, den Strahlenden in seinem Wagen, in seinem Himmelswagen, vielleicht ist sein Sohn, der Sänger, deshalb so fad, so träge, die Mädels machen ja die ganze Kreischarbeit, er macht ja nichts, er macht nie was, weils schon mit seinem Vater immer nur rauf und runtergegangen ist, und das möchte der Sohn nicht wiederholen, daß er immer der Sonne, seinem Papa, zuschauen muß, rauf, runter, das ist fast so schlimm wie rein, raus, alles, was von den Männern kommt, ist irgendwie eintönig, und bis sie den zweiten Ton beherrschen, das kann dauern. Ohne Sonne wären wir nicht, gut, das gebe ich zu, wir brauchen sie, aber viel ist das nicht, was wir sind, wie leicht geht einer von uns verloren, und mich gibt es ja nicht mehr, aber viel ist das nicht, was es da nicht mehr gibt, und ich kann behaupten: nicht so schlimm, will der Sonnengott mich etwa kontrollieren?, ob ich auch wirklich weg bin, ob ich Schatten bin, den es ja leider ohne ihn auch nicht gibt? Es ist leider wahr: Nur er kann Schatten erzeugen. Gut, darauf hat er ein Monopol. Aber darauf ist er nicht stolz, wie er da immer wieder auftaucht, wie er (wir hören ein brüllendes Wiehern, dann ein zischendes Erlöschen), sich aufbäumend, bremst, herausspringt, schaut, ob auch alle Schatten da sind und ob die Farbe, die er fürs Licht vorgesehen hat, so funktioniert, und das prüft er in genau dem Licht, das er doch selbst erzeugt hat, wie der da auftaucht und wieder abtaucht, alles in langatmiger Stereotypie, ja, genau wie mein Werk, gut, daß Sie mir das sagen, das wäre aber doch nicht nötig gewesen!, ich weiß das selber, ich weiß, mein Werk ist eintönig, aber sein Weg ist es genauso: eintönig, es gibt ja nur die Himmelsstraße, die Sie sich ruhig als öde Umgehungsstraße irgendwo in der Pampa vorstellen dürfen, und da fährt er, und da gehts rauf und wieder runter, mich hat er ausgeblendet, wie so viele, wie früher oder später alle; mich sieht er nicht mehr, ich bin schon fort, wie er da also auftaucht, der Apoll, der Schweiger, äh, 
Schwieger-Papi!, weiß er schon, daß ihm nichts übrigbleiben wird als wieder abzutauchen, zu verschwinden, zwar nur für ein paar Stunden, aber immerhin, auf der Erde hat er dann nichts zu suchen. Er muß genauso weg wie ich, wenn auch nicht für immer. Er kommt wieder. Er kommt immer wieder. Im Gegensatz zu mir verschwindet er nie für immer, der Gott der Sonne, er fällt, aber er steht immer wieder auf und fährt weiter. Sonst wäre es doch immer finster. Und nicht einmal sein Sohn, der Sänger, sieht mich noch, das macht ihn ja fertig, ja, das macht den fertig!, denn er kann mich ja nur in Bezug auf sich überhaupt erkennen, klar, das können viele, keine große Leistung, aber aber aber, was wollte ich sagen, der Übergang von diesem Körperschmerz, der sich immer einstellen wird, wenn er das Fehlen seines Objekts, in diesem Fall mein Fehlen, erkennen muß, der entspricht dem Wandel, ach was, der Übergang von Ichweiß zu Ichweißnicht entspricht normalerweise, bei normalen Menschen, die keine Sänger sind, gar nichts, keine Entsprechung, kein Treffer, bei normalen Menschen findet das keine Entsprechung, oder ich kenne sie nicht, die Normalen. Genau! Da rackern sich welche auf der Bühne ab, und die kleinen Mädchen mit ihren Fotzenhobelmündern, die grade nur drei Töne beherrschen, einen oben, einen unten und einen in der Mitte, und keiner davon ist angenehm für den menschlichen Genuß, die kreischen sich aus den strengen, strafenden Mienen ihrer Mütter davon, die einst selbst mit Zelten zu Festivals in den Schlamm eilten, wo die Dixi-Klos überflossen von den starken inneren Rührungen. Wie herrlich diese Erinnerung und diese dort auch! Bei unseren Stars ist das natürlich anders, bei denen ist alles anders, aber was soll der Sänger mit denen anfangen, die da vor seinem Gesicht ihr Geschlecht hervorziehen und aufklappen, und das weibliche Geschlecht ist schon in seiner frühesten Phase einfach überall, man kann schauen, wohin man will, die sind einfach überall, die Mädels mit ihren tückischen Spalten, die sind wie Sandhaufen, Sandbänke, Treibsandlöcher, nehmen jeden auf, geben niemand wieder her, sind bereit für einen, der keiner ist, oder für keinen, der einer ist, wer auch immer, am besten eine Gruppe, viele auf einmal!, also denen die alle halt zujubeln, kreisch kreisch kreisch!, beste Großraum-Disco-Wumme!, wir haben also einen Übergang, was wollte ich sagen?, einen Übergang, der bei einem normalen Menschen nicht nichts entspricht, wie ich einmal irrtümlich anmerkte, sondern der entspricht genau dem Wandel von der narzißtischen zur Objektbesetzung, nicht wahr. Der Übergang entspricht also doch etwas, aber dazu müßte man erst mal außer sich selbst auch noch etwas anderes, einen anderen, wenigstens einen!, sehen. Na, einen sehen sie ja, keine Ahnung, nein, ich habe eine Ahnung, welchen, aber ich habe keine Ahnung, ob das wirklich wahr ist, was der Sänger singt. Ich glaube, jetzt ist er ohnedies ruhig. Der Phantomschmerz eines Verlusts bringt den normalen Menschen dazu, sich 
ein andres Objekt zu suchen, das ihm dann gleich wieder Schmerz, zufügen kann. Ganz neuen Schmerz. Aber immerhin Schmerz. Die Leute verdrängen das, weil sie glauben, sie wollen Spaß, dabei wollen sie Schmerz. Je mehr sie haben wollen, desto mehr wollen sie, daß etwas fehlt. Damit sie dann wieder etwas Neues haben können. Wissen Sie noch, daß es mein Fehlen sein wird, das Fehlen des geliebten Objekts, das zum Zwang des Wandels der Objektbesetzung führen muß? Mein Tod? Mein Fehlen? Aber bei ihm nicht, bei ihm nicht, bei ihm funktioniert das irgendwie nicht, das sehe ich jetzt schon voraus. Ich kenne ihn. Er wird sich nicht damit abfinden. Er wird mich finden wollen. Er wird herausfinden wollen, wo ich bin. Er hat mich, sein Objekt, zu hoch gehängt, das war von Anfang an ein Fehler, ein typischer Sängerfehler, falsche Note, das wird seiner Trauer irgendwie eine falsche Note geben, ich höre das jetzt schon, ich horche in die Zukunft hinein, sie ist definitiv falsch, und jeder seiner Töne ist auch falsch, er wird einen falschen Ton singen, das höre ich jetzt schon, bevor er überhaupt ansetzt, sonst hört es keiner, die hören ja nichts, die Kreischerinnen, die hören nur ihn, aber nicht, was, und was sie hören, ist auch nichts, ich aber höre es, er hat mich als sein Objekt viel zu hoch besetzt, kein Wunder, er war der Besetzungschef von mir, seinem Objekt, und er hat mir eine zu hohe Rolle eingeräumt, bitte, ich sage eingeräumt, weil er mir diesen Platz ja erst geschaffen hat, ich habe das nicht getan, aber er, er hat mich zu hoch gehängt, und diese hochbesetzte Objektrolle, die er mir ausdrücklich einräumte (ich habe nicht darum gebeten, das können Sie mir glauben!), spielt ungefähr die Rolle einer von Verletzung betroffenen Körperstelle, die durch Reizzuwachs nur notdürftig bedeckt ist. Tote werden ja für die Daheimgebliebenen immer reizvoller als sie je waren. Er sieht mich nun als Teil seines Körpers, er kann mich gar nicht anders sehen. Klar. Und die Kontinuität und Unhemmbarkeit dieses Besetzungsvorgangs, die der Kontinuität und Unhemmbarkeit seines Schmerzes entspricht, den er als echten, furchtbaren Körperschmerz erfahren muß, bringen einen Zustand hervor, bringen ihn in einen Zustand, der, wie soll ich sagen, ach ja, es hat schon jemand für mich gesagt, danke, also die Kontinuität und die Ungehemdetheit, äh, die Ungehemmtheit, nein, auch nicht, die Unhemmbarkeit bringen dann bei ihm einen Zustand der totalen Hilflosigkeit hervor. Oder verlängern diesen Zustand, denn anders als hilflos habe ich ihn nie erlebt. Ich sehe das schon vor mir, wo ich doch noch im Gras liege und zusehends verschatte und verschrottet werde, von der Höhe kommt ein Blitz, aber er erhellt mich nicht mehr, vom Berg kommt ein Sturm, aber er bewegt mich nicht mehr, was will ich hier, bin doch kein höherer Mensch, der ein Recht hätte? Was will ich hier? Nicht mehr von Haut bedeckt? Schatten? Nicht mehr wesen und nicht mehr wesentlich, aber das war ich ja nie. $[\ldots]$ 


\footnotetext{
* Ruth BOHUNOVSKY - Graduada (1996) e Mestre (1997) em Estudos da América Latina pela Universidade de Viena. Doutora em Linguística Aplicada (2003) pela Universidade Estadual de Campinas. Realizou pesquisa de pós-doutorado na Universidade Estadual de Campinas (2004; 2007), Universidade de Vienna (2006-2007; 2019), Áustria, na Universidade Federal de Santa Catarina (2014-2015). Professora na Universidade Federal do Paraná. Universidade Federal do Paraná, Setor de Ciências Humanas, Departamento de Letras Estrangeiras. Curitiba, Paraná, Brasil.

Currículo acadêmico: http://lattes.cnpq.br/6546130407918031

ORCID: http://orcid.org/0000-0003-4412-2678

E-mail: ruth.bohunovsky@gmail.com
}

** Cristiane Gonçalves BACHMANN - Graduada em Letras - Português (2002) e graduanda em Letras - Alemão (ênfase em Estudos da Tradução) pela Universidade Federal do Paraná. Mestre em Letras (2019) pela mesma instituição. Universidade Federal do Paraná, Setor de Ciências Humanas, Programa de Pós-Graduação em Letras. Curitiba, Paraná, Brasil.

Currículo acadêmico: http://lattes.cnpq.br/4880877211585451

ORCID: http://orcid.org/0000-0003-3335-9020

E-mail: bach.cris@gmail.com

1 “weibliche Sprechen ist [...] eine phallische Anmaßung”. (ROEDER, 2020. s/p. Tradução nossa.).

2 "Überschreitung". (ROEDER, 2020. s/p. Tradução nossa.).

3 “der ist wie ein Säugling, was er hat, das hält er fest, an dem saugt er, und dann spuckt er es wieder aus, und dann singt er gleich wieder fleißig”. (JELINEK, 2013a, s/p. Tradução nossa.).

${ }^{4}$ Recorremos às traduções mais recentes dos textos freudianos "Trauer und Melancholie" (FREUD, 1949) e de "Hemmung, Symptom und Angst" (FREUD, 1926)", feitas por Paulo Cézar de Souza - respectivamente, "Luto e Melancolia" (FREUD, 2010) e "Inibição, Sintoma e Angústia" (FREUD, 2014) -, ambas publicadas pela Companhia das Letras; bem como aos respectivos originais.

5 “Ich schreibe, wen interessierts" (JELINEK, 2013a, s/p. Tradução nossa.).

6 “ich bin nicht mehr da, ich bin." (JELINEK, 2013a, s/p. Tradução nossa.).

${ }^{7}$ Jelinek (2013b).

8 "Meine Stücke verweigern sich dem psychologischen Theater. Die Figuren sprechen nicht aus sich heraus. Sie sind keine Personen, keine Menschen, sondern Sprachschablonen. Sie konstituiren sich aus dem, was sie sagen, nicht aus dem, was sie sind. Sie behaupten etwas von sich, statt auf der Bühne zu leben". (JELINEK, 1989, p. 143. Tradução nossa.).

${ }^{9}$ Para uma leitura mais abrangente sobre a peça, recomendamos o artigo de Artur Sartori Kon (2018).

${ }^{10}$ Texto integral em alemão publicado no site da autora. Disponível em: http://www.elfriedejelinek.com/fschatten.htm Acesso em: 2 fev. 2020.

11 (c) Elfriede Jelinek 2012. Direitos autorais e de execução pública concedidos por Rowohlt Theater Verlag, Hamburgo. Contato: theater@rowohlt.de 